\title{
AVALIAÇÃO DA MICROESTRUTURA DOS AÇOS SAE J403 1045, SAE J403 1075 E DIN100CrV2 APÓS TRATAMENTOS TÉRMICOS*
}

\author{
Tiago Silva Costa ${ }^{1}$ \\ Luana Araújo Batista ${ }^{1}$ \\ Juliana Cristina de Paula ${ }^{1}$ \\ Kleolvane Carlos Figueiredo de Paula ${ }^{2}$
}

\section{Resumo}

Os tratamentos térmicos são um conjunto de operações que têm por objetivo modificar as propriedades dos aços e de outros materiais através de um conjunto de operações que incluem o aquecimento e o resfriamento em condições controladas. Os aços SAE J403 1045, SAE J403 1075 e DIN 100CrV2 são aplicados em diferentes setores industriais graças às diferentes propriedades que podem ser alcançadas através de tratamentos térmicos. Este trabalho visou caracterizar e descrever as fases formadas nos aços SAE J403 1045, SAE J403 1075 e DIN 100CrV2 após tratamentos térmicos de têmpera, normalização e recozimento pleno.

Palavras-chave: Tratamento Térmico; SAE J403 1045; SAE J403 1075; DIN100CrV2.

\section{MICROSTRUCTURE ASSESSMENT OF STEEL SAE J403 1045, SAE J403 1075 AND DIN100CRV2 AFTER HEAT TREATMENT}

\section{Abstract}

The thermal treatments are a set of operations which aims to modify the properties of steels and other materials through a set of operations that include heating and cooling under controlled conditions. The steels SAE J403 1045, SAE J403 1075 and DIN 100CrV2 are applied in different industrial sectors thanks to the different properties that can be achieved through heat treatments. This work aimed to characterize and describe the phases formed in SAE J403 steels 1045, SAE J403 1075 and DIN $100 \mathrm{CrV} 2$ after heat treatment of tempering, normalization and full annealing.

Keywords: Heat Tratament; SAE J403 1045; SAE J403 1075; DIN100Crv2.

1 Graduando em Engenharia Metalúrgica, Centro Universitário do Leste de Minas Gerais - Unileste, Associado ABM Júnior, Coronel Fabriciano, Minas Gerais, Brasil.

2 Graduando em Engenharia Metalúrgica no Centro Universitário do Leste de Minas GeraisUnileste. Coronel Fabriciano, Minas Gerais, Brasil. 


\section{INTRODUÇÃO}

Os aços SAE J403 1045, SAE J403 1075 e DIN100CrV2 podem ser aplicados em diversos setores industriais. Enquanto os aços SAE J403 1045 e SAE J403 1075 são aplicados principalmente em ferramentas para a construção civil, implementos agrícolas e autopeças, o aço DIN100CrV2 possui as propriedades almejadas para aplicação em ferramentas de corte e trabalho a frio.

As propriedades dos aços são diretamente dependentes da sua composição química e de sua microestrutura. Uma das formas de alterar a microestrutura dos aços e as suas propriedades, sem alterar sua a composição química, é através de tratamentos térmicos. Chiaverini [1] define tratamento térmico como um conjunto de operações de aquecimento e resfriamento dos metais, sob condições controladas de temperatura, tempo, atmosfera e velocidade de resfriamento, com o objetivo de alterar suas propriedades ou conferir-lhe as características adequadas a determinadas aplicações na engenharia.

Souza [2] destaca que o resfriamento é uma das variáveis mais importantes dos processos de tratamentos térmicos, pois é ele que determinará a estrutura formada e, consequentemente, as propriedades finais do material. Os meios usuais de resfriamento são: ambiente do forno, ao ar e meios líquidos. O meio de resfriamento mais brando é dentro do forno, sendo ao ar um pouco mais severo e em meios líquidos mais severos ainda [3-4].

Este trabalho visa verificar as fases formadas nos aços SAE J403 1045, SAE J403 1075 e DIN100CrV2 após os tratamentos de têmpera, normalização e recozimento pleno.

\section{MATERIAIS E MÉTODOS}

Para realização deste estudo, foram utilizadas amostras dos aços SAE J403 1045, SAE J403 1075 e DIN100CrV2, todas originadas de tiras laminadas a quente com $3 \mathrm{~mm}$ de espessura. O aço SAE J403 1045 é um aço de médio carbono com composição básica de 0,45C; 0,75Mn; 0,6 Si máx., 0,04 P máx. e 0,05 S máx. $O$ SAE J403 1075 possui composição básica de 0,75C; 0,60Mn; 0,04 P máx. e 0,05 S máx. E o DIN100CrV2 é um aço hipereutetóide, de composição química básica $1,0 \mathrm{C} ; 0,6 \mathrm{Mn} ; 0,85 \mathrm{Cr}$ e $0,3 \mathrm{~V}$.

Para cada grupo de aço foram preparadas quatro amostras com dimensão de $20 \mathrm{X}$ $20 \times 3 \mathrm{~mm}$. Três amostras dos aços SAE J403 1045, SAE J403 1075 foram aquecidas a $810^{\circ} \mathrm{C}$ com tempo de encharque de 20 minutos. Uma amostra de cada aço foi submetida aos tratamentos térmicos de têmpera em água, normalização e recozimento pleno. A quarta amostra de cada aço não foi tratada termicamente. Para tratamento das amostras do aço DIN100CrV2, antes de inserir as amostras no forno, a temperatura foi elevada para $950^{\circ} \mathrm{C}$, com o objetivo de solubilizar todos os elementos presentes. O tempo de aquecimento foi o mesmo das demais amostras e foram realizados os mesmos tratamentos térmicos.

Após tratamento térmico as amostras preparadas para análise metalográfica. $O$ ataque químico foi realizado com solução de Nital $4 \%$ e as análises realizadas no microscópio ótico no aumento de 500x. 


\section{RESULTADOS E DISCUSSÃO}

\subsection{Aço SAE J403 1045}

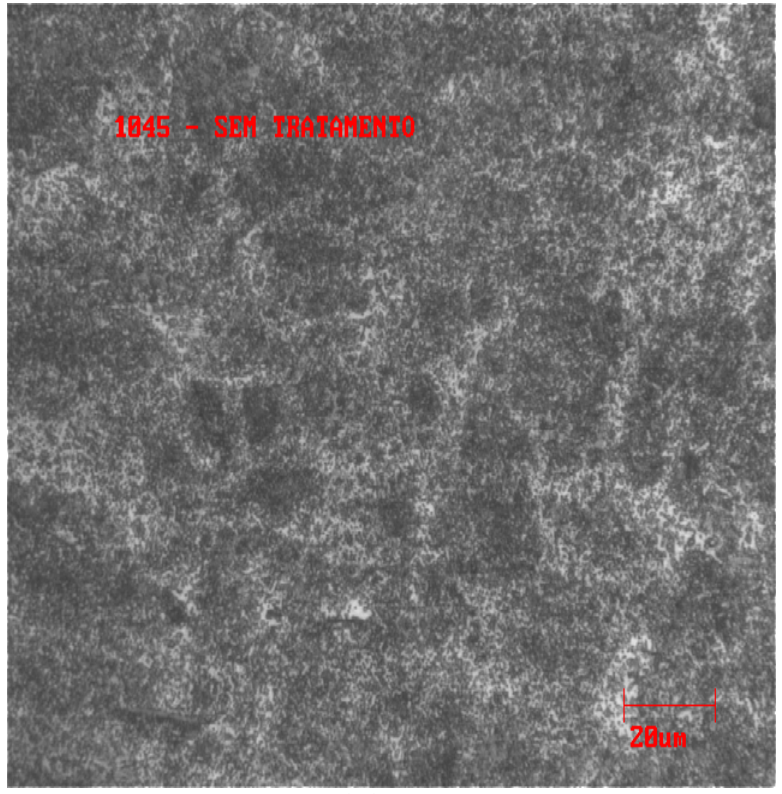

(a)

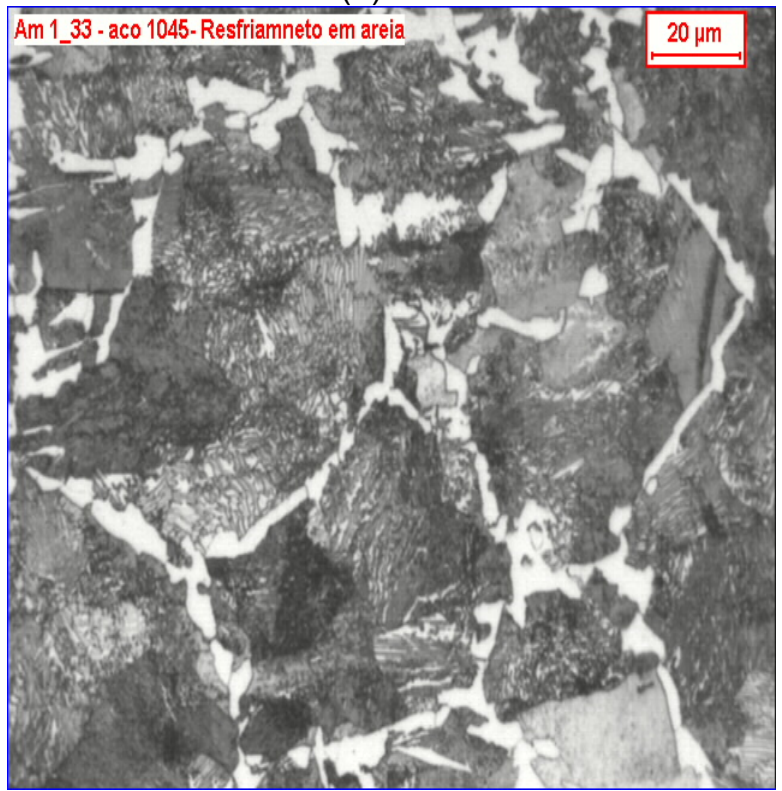

(c)

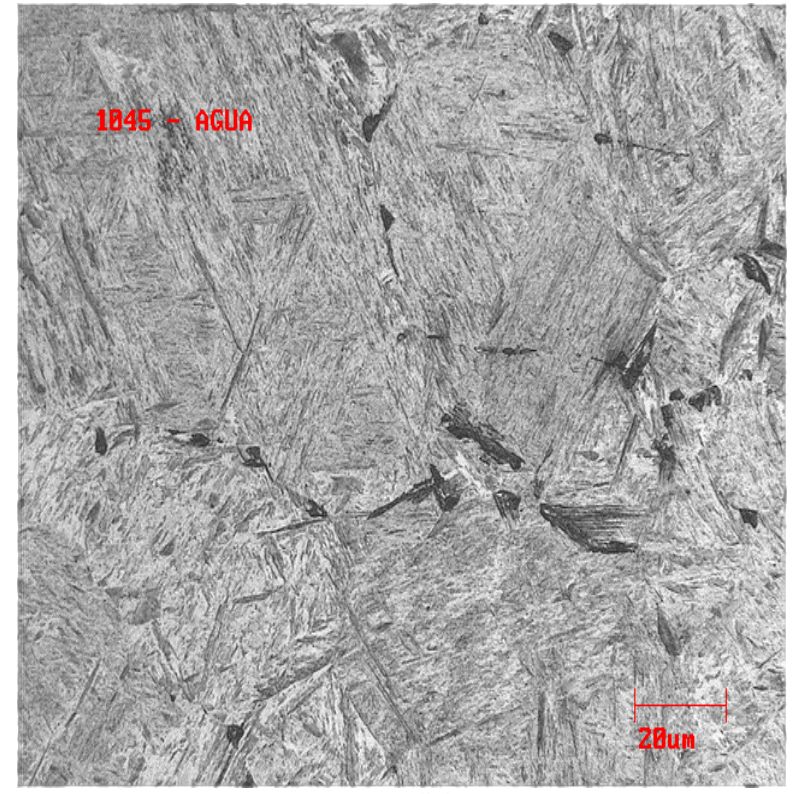

(b)

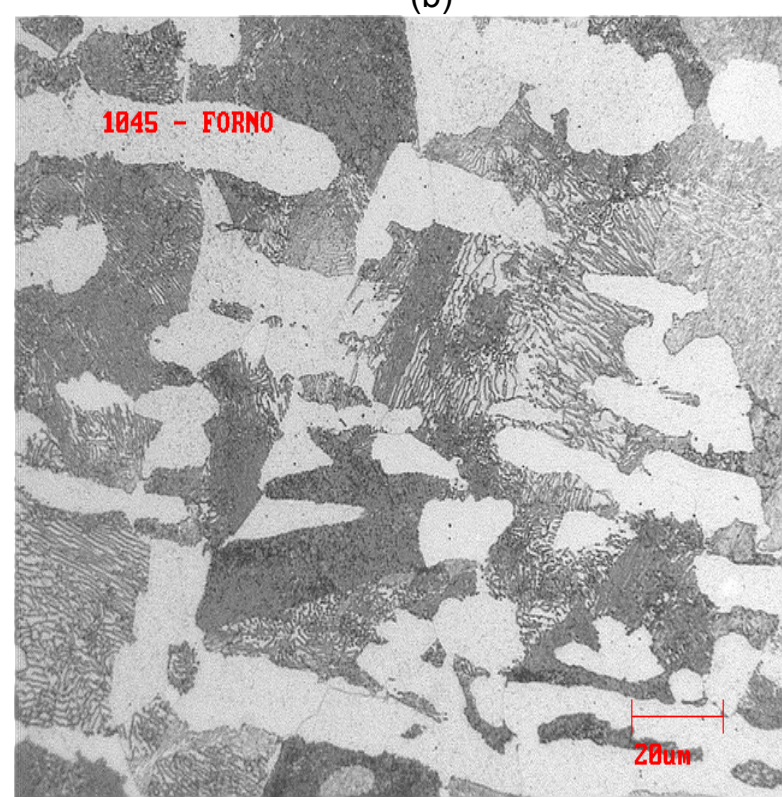

(d)

Figura 1. Microestrutura do aço SAE J403 1045 após tratamentos térmicos de (a) laminado a quente, (b) têmpera, (c) normalização e (d) recozimento pleno.

A Figura 1(a) apresenta a microestrutura do aço laminado a quente, ou seja, a estrutura de partida das amostras, constituída de uma estrutura fina de ferrita proeutetóide e perlita. A Figura 1(b) possui estrutura martensítica com carbonetos que provavelmente não foram dissolvidos, decorrentes de um tempo de encharque insuficiente. A formação dessa estrutura é favorecida devido à elevada taxa de extração do calor sofrida pelo material.

$\mathrm{Na}$ Figura(c) observa-se uma estrutura perlítica com formação de ferrita proeutetóide nos contornos de grão. A Figura 1(d) apresenta estrutura com granulação grosseira de ferrita proeutetóide e perlita. A transformação em temperaturas mais altas 
significa menor taxa de nucleação, devido à menor força motriz, resultando em maiores grãos de ferrita proeutetóide e perlita mais grosseira. Também a fração de ferrita proeutetóide é maior, aproximando mais daquela que se calcula no diagrama de fase. Estes grãos de ferrita nucleiam também nos contornos da austenita, mas em menor número e crescem mais, por isso não delineiam os contornos da austenita como na Figura 1(c).

\subsection{Aço SAE J403 1075}

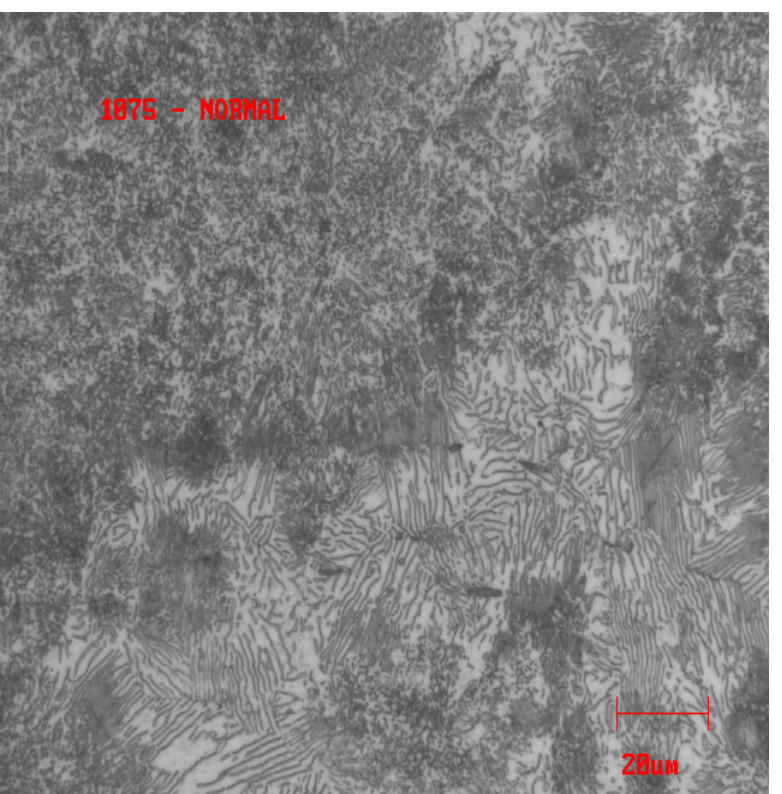

(a)

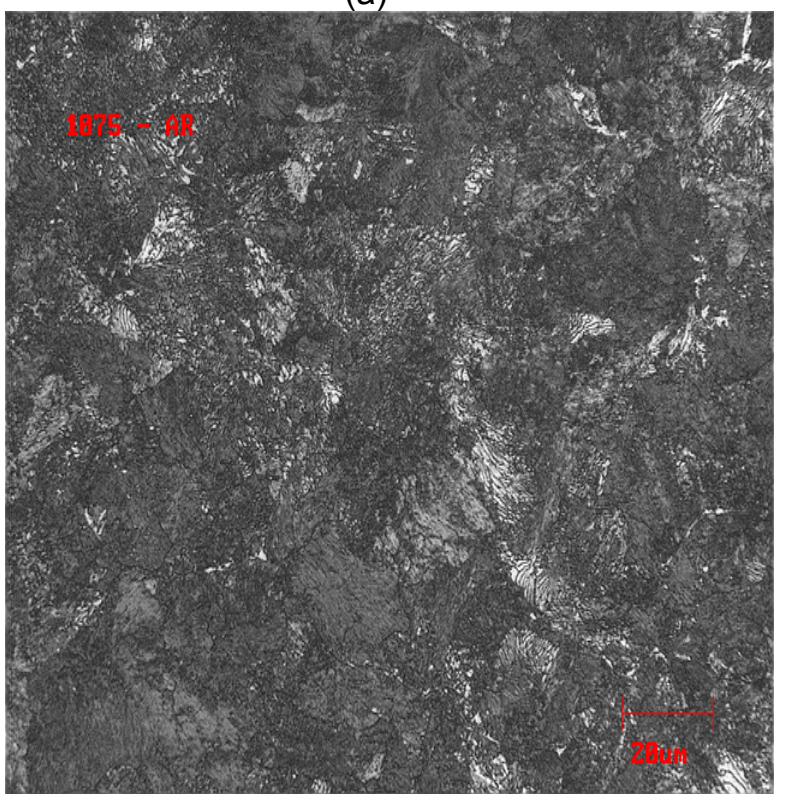

(c)

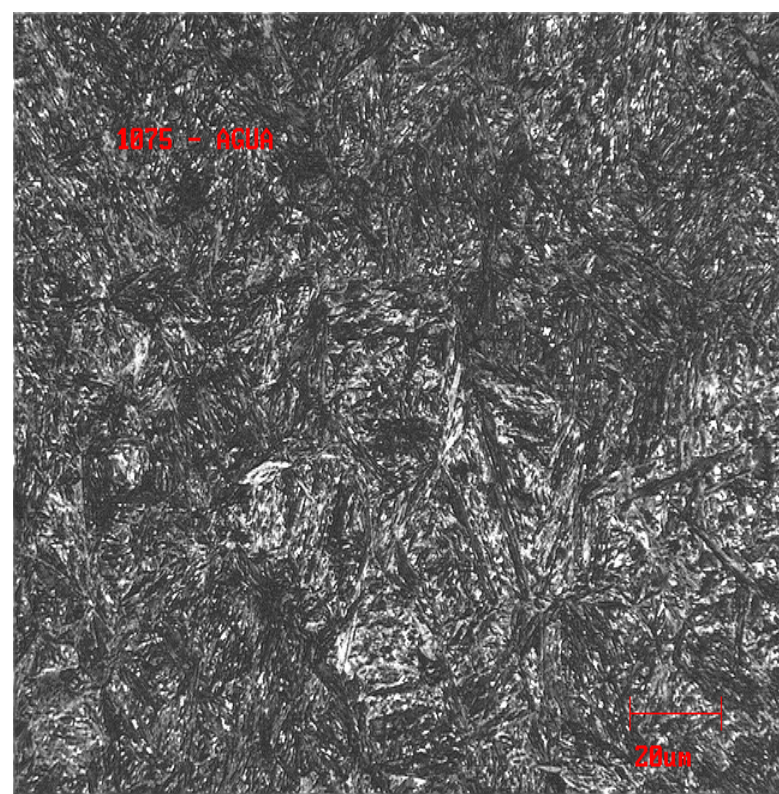

(b)

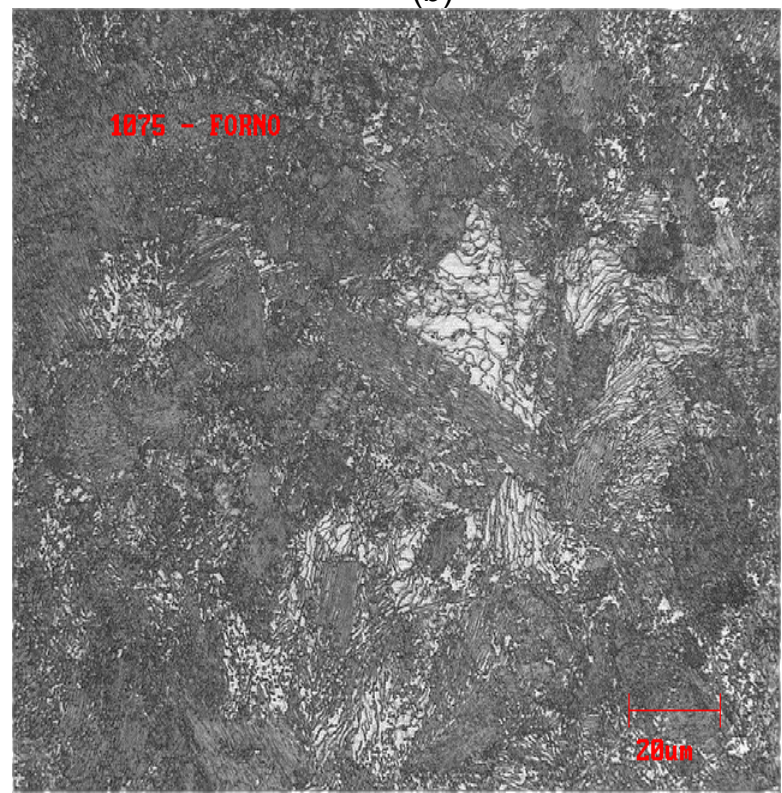

(d)

Figura 2. Microestrutura do aço SAE J403 1075 após tratamentos térmicos de (a) recozimento, (b) têmpera, (c) normalização e (d) recozimento pleno.

Na Figura 2(a) algumas regiões mostram a presença de perlita e outras que sugerem uma quebra das lamelas e início de globulização, que pode ser devido ao resfriamento lento após bobinamento da tira laminada a quente. A amostra temperada, Figura 2(b), apresenta morfologia de martensita e os campos mais 
escuros sugerem a presença de carbonetos. As Figuras 2(c) e 2(d) revelam perlita, porém a estrutura da Figura 2(d) é mais grosseira.

\subsection{Aço DIN100CrV2}

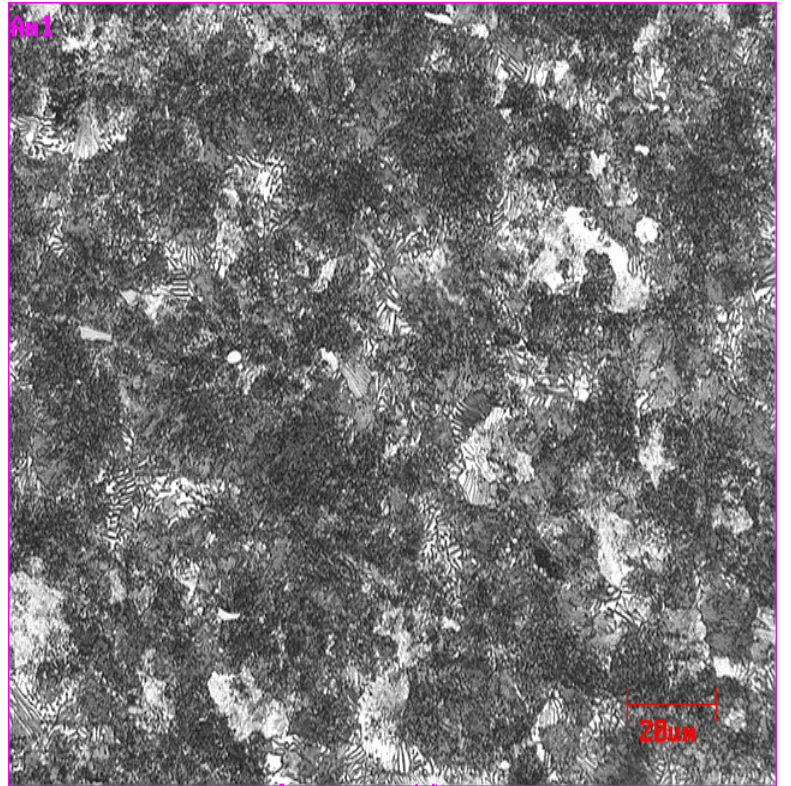

(a)

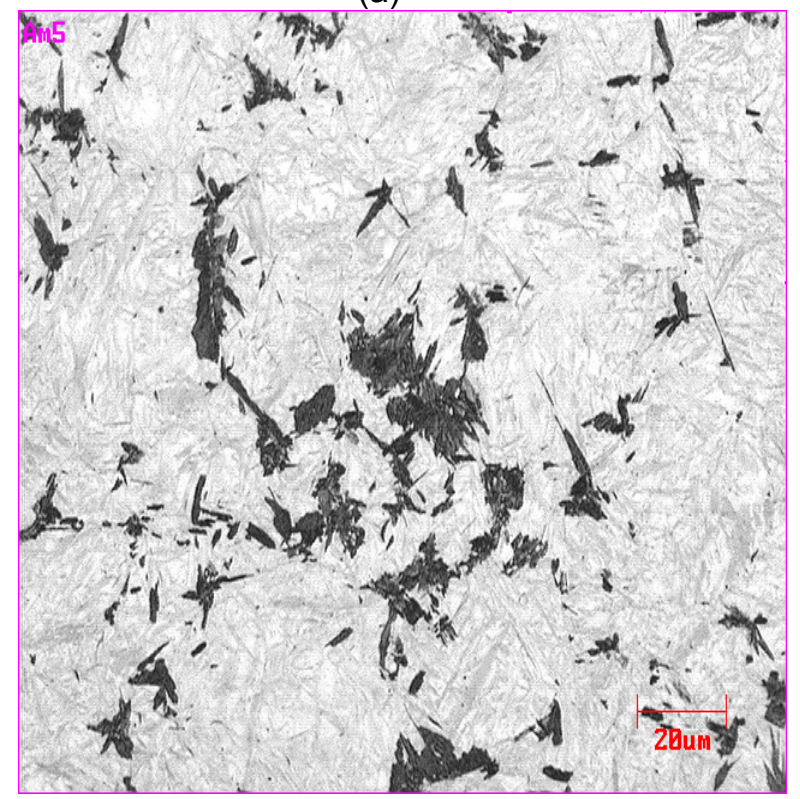

(c)

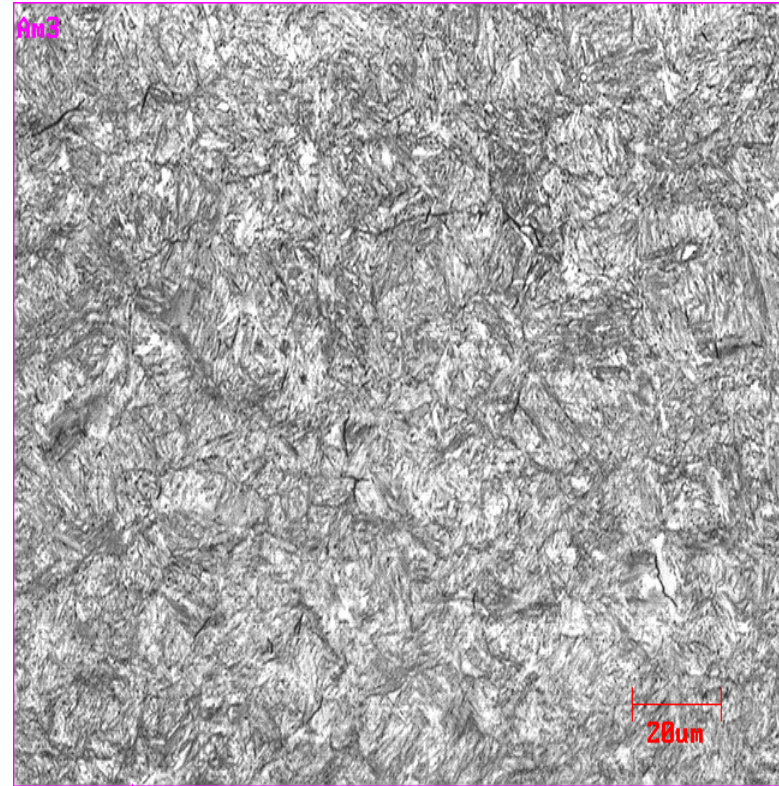

(b)

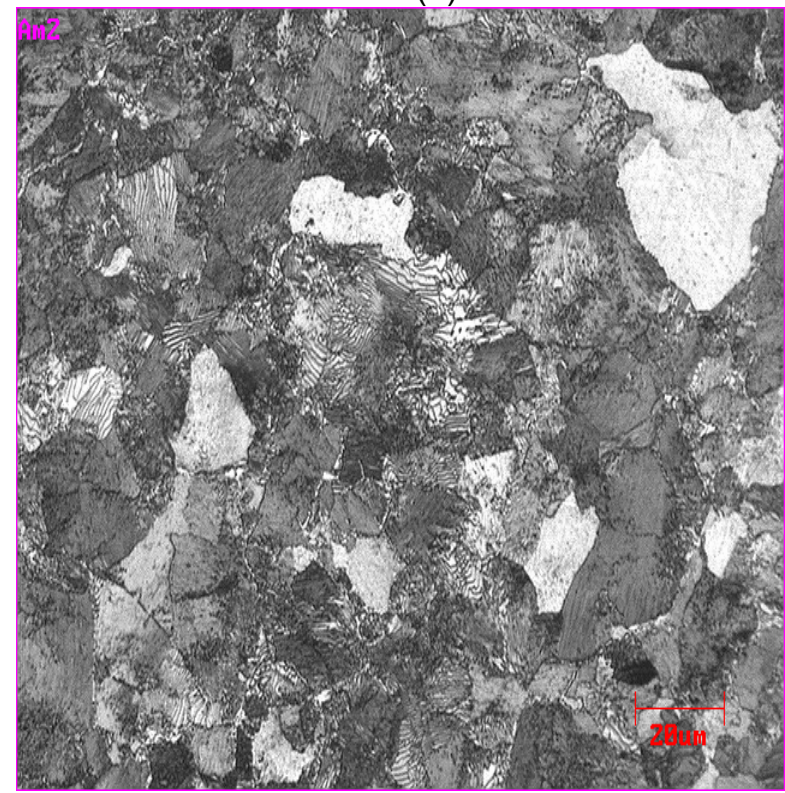

(d)

Figura 3. Microestrutura do aço DIN100CrV2 após tratamentos térmicos de (a) recozimento, (b) têmpera, (c) normalização e (d) recozimento pleno

Observa-se que a amostra da Figura 3(a) é constituída de perlita e bainita. Na Figura 3(b) a matriz é totalmente martensítica. A microestrutura normalizada, Figura 3(c), é constituída de martensita, bainita e carbonetos. No material recozido plenamente, Figura 3(d), a microestrutura é constituída de perlita fina, perlita grossa e carbonetos. 


\section{CONCLUSÃO}

Um mesmo aço apresenta microestruturas diferentes quando submetido a variados tipos de tratamento térmico. Em todas as amostras analisadas, independente do tipo de aço, a microestrutura após o tratamento térmico foi diferenciada entre as condições submetidas, seja essa diferença pelas fases e constituintes formados, como pelo tamanho de grão adquirido.

As fases formadas são influenciadas pelos elementos de liga do aço, principalmente pelo carbono. Como os aços analisados apresentavam teores de carbono diferentes, observou-se a diferença da constituição dos aços após cada tratamento térmico, exceto na têmpera, da qual em todas as amostras a estrutura obtida foi martensítica.

\section{Agradecimentos}

Ao professor Marco Antônio da Cunha.

\section{REFERÊNCIAS}

1 Chiaverini, V. Aços e ferros fundidos: Características gerais, tratamentos térmicos, principais tipos. 7a Edição. São Paulo: Associação Brasileira de Metalurgia e Materiais; 1996.

2 Souza, G. "Influência do tratamento térmico de recozimento de recristalização em aço SAE 1010 deformado plasticamente a frio". Monografia. Ouro Preto: Universidade Federal de Ouro Preto; 2006.

3 Colpaert, H. Metalografia dos Produtos Siderúrgicos Comuns. 4a Edição revista e atualizada por André Luiz V. da Costa e Silva. São Paulo: Editora Blucher; 2008.

4 Silva, A. L. V da C. Aços e Ligas Especiais. 2a Edição. São Paulo: Editora Blucher; 2006. 